\title{
Seismic Response Analysis and Control of Frame Structures with Soft First Storey under Near-Fault Ground Motions
}

\author{
Chunyang Liu $\mathbb{D}^{1,2}$, Peng Sun ${ }^{10}{ }^{1}$ and Ruofan Shi ${ }^{1}$ \\ ${ }^{1}$ Department of Civil Engineering, Shandong Jianzhu University, Jinan 250101, China \\ ${ }^{2}$ Key Laboratory of Building Structural Retrofitting and Underground Space Engineering (Shandong Jianzhu University), \\ Ministry of Education, Beijing, China \\ Correspondence should be addressed to Chunyang Liu; liucy2011@sdjzu.edu.cn
}

Received 28 September 2019; Revised 18 January 2020; Accepted 21 January 2020; Published 30 March 2020

Academic Editor: Belén González-Fonteboa

Copyright (c) 2020 Chunyang Liu et al. This is an open access article distributed under the Creative Commons Attribution License, which permits unrestricted use, distribution, and reproduction in any medium, provided the original work is properly cited.

This paper proposes two kinds of arrangements of buckling-restrained brace dampers to strengthen soft-first-storey structures locally. Two types of near-fault ground motion, with and without pulse, were selected for a study of the seismic response characteristics of soft-first-storey structures with and without buckling-restrained brace dampers, and the effects of different bracing arrangements on improving the seismic performance of soft-first-storey structures were recognized. The results show that, compared with pulse-free ground motion, near-fault pulsed ground motion results in a more severe seismic response in soft-firststorey frame structures, leading to more serious and rapid destruction of the main structure. Buckling-restrained brace dampers have an obvious energy dissipation effect, play a better role in protecting the main structure, and have good practicality. Compared with structures in which the buckling-restrained brace dampers are arranged only on the bottommost layer, the bottom-fourlayer-support structure is more advantageous in terms of seismic performance.

\section{Introduction}

According to earthquake disaster investigation data, cities located near faults in extreme earthquake zones are seriously damaged whenever earthquakes occur, resulting in large numbers of casualties and serious property losses. The characteristics of near-fault ground motion and the corresponding seismic responses of engineering structures have therefore received extensive attention and research interest from academics in the engineering community. With the rapid development of digital techniques for studying strong earthquakes, a large number of valuable near-fault ground motion records have been obtained on several famous earthquakes in the world, such as the 1989 Loma Prieta earthquake in California, the 1994 Northridge earthquake, also in California, the 1995 Kobe earthquake in Japan, the 1999 Kocaeli earthquake in Turkey, the 2008 Wenchuan earthquake in China, and the 2018 Hualien earthquake in Taiwan. These data promoted studies on the characteristics of near-fault ground motion, which are found to be different from those of mid- and far-field ground motions.

Near-fault ground motion is affected by factors such as site conditions, focal mechanism, and fault rupture process, reflecting the long-period velocity pulse effect caused by directivity effect and fling-step effect, rich lowfrequency components, and large ground motion amplitude $[1,2]$. The velocity pulse effect of near-fault ground motion generally occurs in the early stage of the velocity time history and has a short duration; the velocity peak is high and involves a higher amount of energy, which is concentrated mainly in the long-period segment, causing serious destruction to long-period structures. Because of the long natural vibration period of a soft-firststorey frame structure, it will be significantly impacted by near-fault pulse-type ground motion. The earthquake damages of the 2018 Hualien earthquake in Taiwan and the 2008 Wenchuan earthquake in China reveal the following $[3,4]$ : 
(i) The bottom layers of many frame structures were seriously damaged, whereas the upper floors had only slight damages.

(ii) There were many "soft-footed buildings," where the bottom layers of the buildings had completely collapsed, and the upper floors had fallen directly on the collapsed ground floors.

(iii) The concrete structures at the bottoms of the columns had detached, and the rebars had yielded.

(iv) The column-end hinges were seriously damaged and produced large residual deformations, whereas the beam-end hinges were only slightly damaged, reflecting the failure mechanism of the "strong beam weak column."

In recent years, the process of urbanization has developed rapidly, and constructions on land have become increasingly tense. The bottom layers of an increasing number of frame structures are either garages or commercial establishments, whereas the upper parts are used as office buildings or residential spaces. The main characteristics of this kind of structure are that the bottom space is large, the layer height is high, and the stiffness of the bottom layer is much lower than that of the upper adjacent layer, resulting in a soft-first-storey structure $[5,6]$. Because the structure has unique use functions and great development potential, a wise development path would be to find a seismic system that can greatly improve the seismic capacity of the building while having a low impact on its unique use functions. At present, researchers from around the world have performed a series of studies on how to improve the seismic performance of the soft-first-storey structure. These improvements involve the following main aspects:

(1) Improving the structure's own ductility. The problems of adding support and reasonable configuration of support for the soft-first-storey structure have been investigated in a study [7], wherein the results indicated that a reasonable arrangement of support allows the underlying weak layer displacement and vertex displacement to be effectively controlled. Cement-lime binder has also been replaced using different amounts of silica fume and perlite powder, and the effects of silica fume-perlite powder on the compressive strength and microstructure of self-compacting concrete have been studied. Based on an analysis of the 28-day and 90day compressive strength of the concrete, the optimum amounts of different additives have been obtained [8]. Meanwhile, after the number of supports has been determined, the support-frame structures of 3-layer and 9-layer structures have been analysed using the pushover method, and the structural system has been studied in combination with experiments [9]. The experiment results revealed that the support-frame system can reduce the overall displacement and improve the bearing capacity of the structure.
(2) Applying shock absorption technology. The seismic performance of a soft-first-storey structure with fibre-concrete damper has been studied via shaking table tests [10]. The experiment results indicated that a fibre-concrete damper can sufficiently control the deformation between layers and can become inelastic before the main member, thus protecting the whole structure. Meanwhile, with the use of a general damage index method (GDI) based on energy, an optimal design method with additional viscous dampers has been proposed for irregular shear frames, but its computational design method was complex [11]. A reinforced-concrete (RC) damperrestricted bracing system has also been used to reinforce the large-space structure at the bottom of a building, and shaking table tests have shown that this system had superior seismic performance [12]. The damper yielding can partially consume some seismic energy and improve the ductility of the frame structure, whereas the limit bracing greatly improves the bearing capacity of the later stages of the structure. In that study, the optimal percentages of microstructure, polypropylene, and hybrid fibre have been determined via tensile and compressive tests, and the effects of using optimum amounts of fibre in the concrete sheaths of buckling-restrained braces (BRB) have been investigated [13]. The study revealed the maximum number of loading cycles, the coefficient of ductility, the energy absorption, and the maximum amount of applied force in the specimen produced by the composition of polypropylene and sinusoidal metal fibre. On the other hand, an analysis of the aseismic performances of a steel-reinforced concrete (SRC) transfer structure with supplemental energy dissipation haunch brace has been performed using the ETABS engineering software [14]. The study results indicated that the viscous energy dissipation haunch brace had a better damping effect on the structure. A design method that uses damped bracings to control a structure with weak storeys has also been studied [15]. The study results revealed that this simplified design method can precisely control the displacement between the weak storeys to a target.

(3) Applying seismic isolation technology. When a softfirst-storey frame structure with serious damage from the Wenchuan earthquake was reinforced through the setting of isolation bearings on the top of the column at the first floor, the weak layer was transformed into an isolation layer, thus restoring its function [16]. Basic isolation theory has also been applied to first-level column top isolation, and nonlinear dynamic analysis has been performed on a project [17]. The study demonstrated that the seismic performance of the structure can be improved by setting isolation bearings on the top of the column. Meanwhile, based on a practical five-storey frame structure as an example, the seismic responses of 
structures with and without isolation bearings have been analysed [18]. The study results indicated that isolation technology on the top of the column could improve the seismic performance of the soft-firststorey frame structure, thus increasing the deformation capacity of the first floor. Through the aforementioned research, the use of isolation technology in the soft-first-storey structure has been concluded to be able to effectively reduce seismic energy input, significantly improve the seismic performance of the original structure, and improve upon the weakness of the first layer.

As of the present, most researches on soft-first-storey frame structures have performed their analyses under the action of conventional ground motion. On the other hand, seismic response analysis on soft-first-storey frame structures under near-fault ground motion is insufficient, and techniques on how to improve the seismic collapse resistance of soft-first-storey frame structures under near-fault ground motion require further research.

In this study, a finite-element model of a 10-storey reinforced-concrete frame structure with soft first storey was established using SAP2000 civil-engineering software. Two kinds of arrangements of BRB dampers were proposed to strengthen the soft-first-storey structure locally. Two types of near-fault ground motion, with and without pulse, were selected for a study on the seismic response characteristics of soft-first-storey structures with and without BRB dampers, and the effects of different bracing arrangements on improving the seismic performance of a structure with a soft first storey were recognized.

\section{Project Overview and Model Building}

2.1. Project Overview. The 10-storey reinforced-concrete frame structure in this study had a 1st storey with a height of $4.3 \mathrm{~m}, 2 \mathrm{nd}$ to 10 th storeys with heights of $3.3 \mathrm{~m}$ each, a total height of $34 \mathrm{~m}$, and a plane size of $42 \mathrm{~m} \times 15.9 \mathrm{~m}$. The seismic fortification intensity was 7 degrees, the seismic level was secondary, and the design seismic acceleration was $0.15 \mathrm{~g}$. The site category was Class II, and the design earthquake group was the second group. The cross section of the beam of the first floor had an area of $300 \mathrm{~mm} \times 600 \mathrm{~mm}$, and that of the column had an area of $650 \mathrm{~mm} \times 650 \mathrm{~mm}$; the beam sections of floors 2 to 10 had areas of $350 \mathrm{~mm} \times 700 \mathrm{~mm}$ each, and the column sections had areas of $700 \mathrm{~mm} \times 700 \mathrm{~mm}$ each. The concrete strength grade of the beams, plates, and columns was $\mathrm{C} 30$. The main reinforcement of the beams and columns was HRB400, and the stirrup was HRB335. The floor constant load was assumed to be $6.0 \mathrm{kN} / \mathrm{m}^{2}$, and the live load was assumed to be $2.0 \mathrm{kN} / \mathrm{m}^{2}$; the roof constant load was assumed to be $7.0 \mathrm{kN} / \mathrm{m}^{2}$, and the live load $0.5 \mathrm{kN} / \mathrm{m}^{2}$; the internal and external wall loads were uniformly assumed to be $8.0 \mathrm{kN} / \mathrm{m}$ each. The structural layout is shown in Figure 1.

2.2. Model Building. The finite-element analysis model of the structure was established using SAP2000 civil-engineering software. The beams and columns were simulated by frame unit, and the floors were simulated by membrane unit. Plastic hinges were set at relative positions, with respect to the beam and column elements, of 0.1 and 0.9 , respectively. The columns were provided with coupled axial force and biaxial moment- (PMM-) related hinges, and the beams were provided with M3 type plastic hinges. The BRB dampers were simulated using plastic units and the Bouc-Wen mechanical model.

During an earthquake, the soft-first-storey frame structure is prone to large interlayer displacement deformation. Therefore, two different support arrangements were established to locally strengthen the soft-first-storey frame structure. Based on the principle of "stiffness compensation," the BRB dampers were designed with the parameters listed in Table 1. Two different BRB damper arrangements are shown in Figures 2 and 3. Figure 2 shows the bottom-support structure model. The $Y$-direction BRB dampers were positioned onto the two-side spans of the 1st, 4 th, 5th, and 8 th axes of the first layer, whereas the $X$ direction $\mathrm{BRB}$ dampers were set onto the two-side spans of the $A$ and $D$ axes of the first layer. Figure 3, on the other hand, shows the bottom-four-layer-support structure model. The $Y$-direction BRB dampers were positioned onto the two-side spans of the 1 st, 4 th, 5 th, and 8 th axes of the first layer and the 1st and 8th axes of the second to fourth layers, whereas the $X$-direction BRB dampers were set onto the two-side spans of the A and D axes of the first to fourth layers.

\section{Structural Dynamic Characteristics}

Modal analysis was performed on the aforementioned three finite-element models, that is, unsupported structure, bottom-support structure, and bottom-four-layer-support structure, and the first 3 modes were extracted for comparison. The first 3 modes of the unsupported structure were $T_{1}=1.204 \mathrm{~s}, T_{2}=1.177 \mathrm{~s}$, and $T_{3}=1.115 \mathrm{~s}$; the first 3 modes of the bottom-support structure were $T_{1}=1.104 \mathrm{~s}$, $T_{2}=1.082 \mathrm{~s}$, and $T_{3}=0.989 \mathrm{~s}$; and the first 3 modes of the bottom-four-layer-support structure were $T_{1}=1.058 \mathrm{~s}$, $T_{2}=1.032 \mathrm{~s}$, and $T_{3}=0.896 \mathrm{~s}$. The first 3 modes of the three structural models had the same vibration directions. The first mode was horizontally vibrated in the $Y$-direction, the second mode was horizontally vibrated in the $X$-direction, and the third mode was twisted around the $Z$-axis.

According to the analysis data, the period ratio (the ratio of the first natural vibration period dominated by torsion to the first natural vibration period dominated by translation) of the unsupported structure was 0.926 , which exceeds the 0.9 limit specified in the code for seismic design of buildings [19], and the torsional effect was obvious. After support was added to the bottommost layer, the structural period ratio became 0.895, which was lower than the 0.9 limit and therefore meets the specified requirements, and the torsional effect was reduced. On the other hand, the period ratio of the bottom-four-layer-support structure was 0.846 , and the torsional effect was further improved compared with that in the bottom-support structure. 


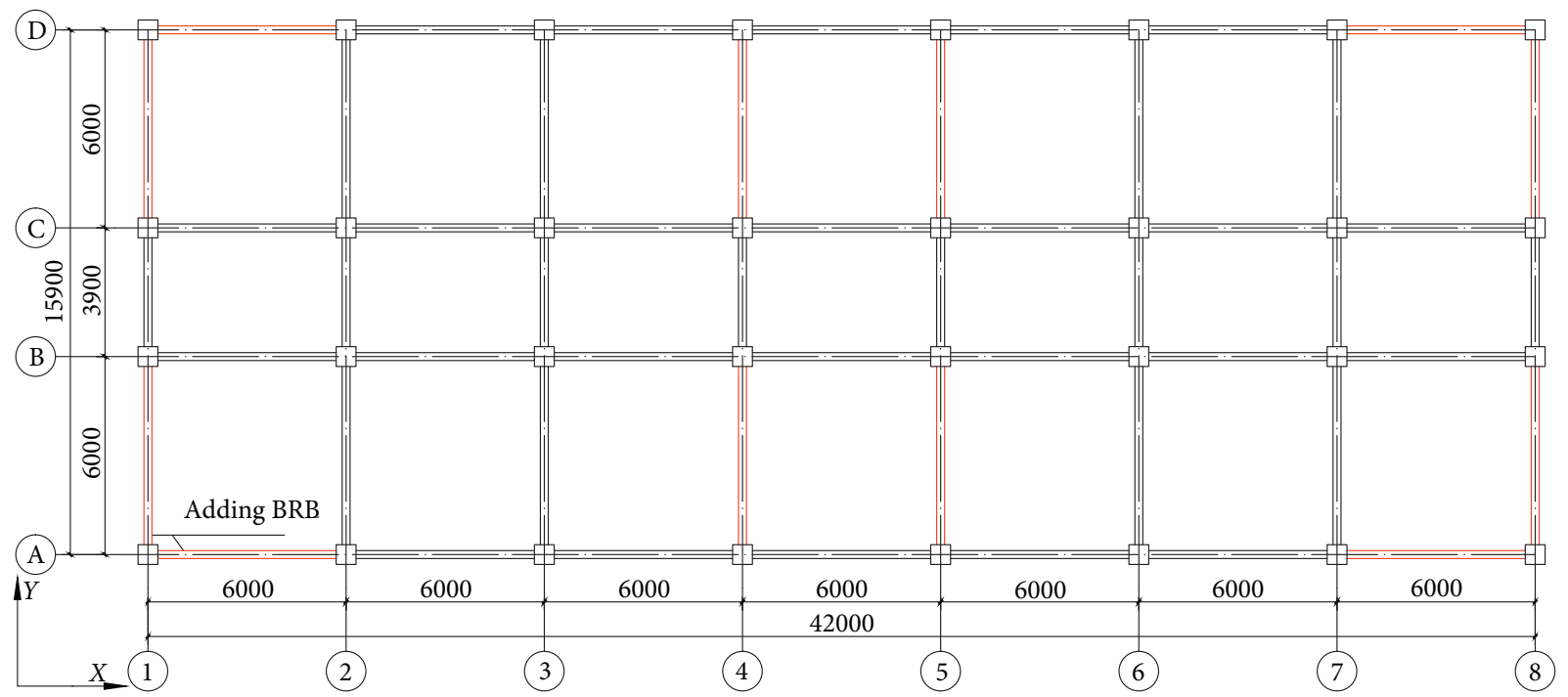

FIgURE 1: Structural layout.

TABLE 1: Buckling-restrained brace (BRB) damper parameters.

\begin{tabular}{lcccc}
\hline Floor & Support number & Core cross-sectional area $\left(\mathrm{mm}^{2}\right)$ & Yield-bearing capacity $(\mathrm{kN})$ & Axial stiffness $(\mathrm{N} / \mathrm{mm})$ \\
\hline 1 & BRB1-1 & 3292 & 967 & 131841 \\
& BRB1-2 & 2894 & 850 & 115929 \\
2 & BRB2-1 & 1703 & 500 & 68193 \\
3 & BRB2-2 & 1419 & 417 & 56827 \\
4 & BRB3-1 & 1135 & 333 & 53446 \\
\hline
\end{tabular}
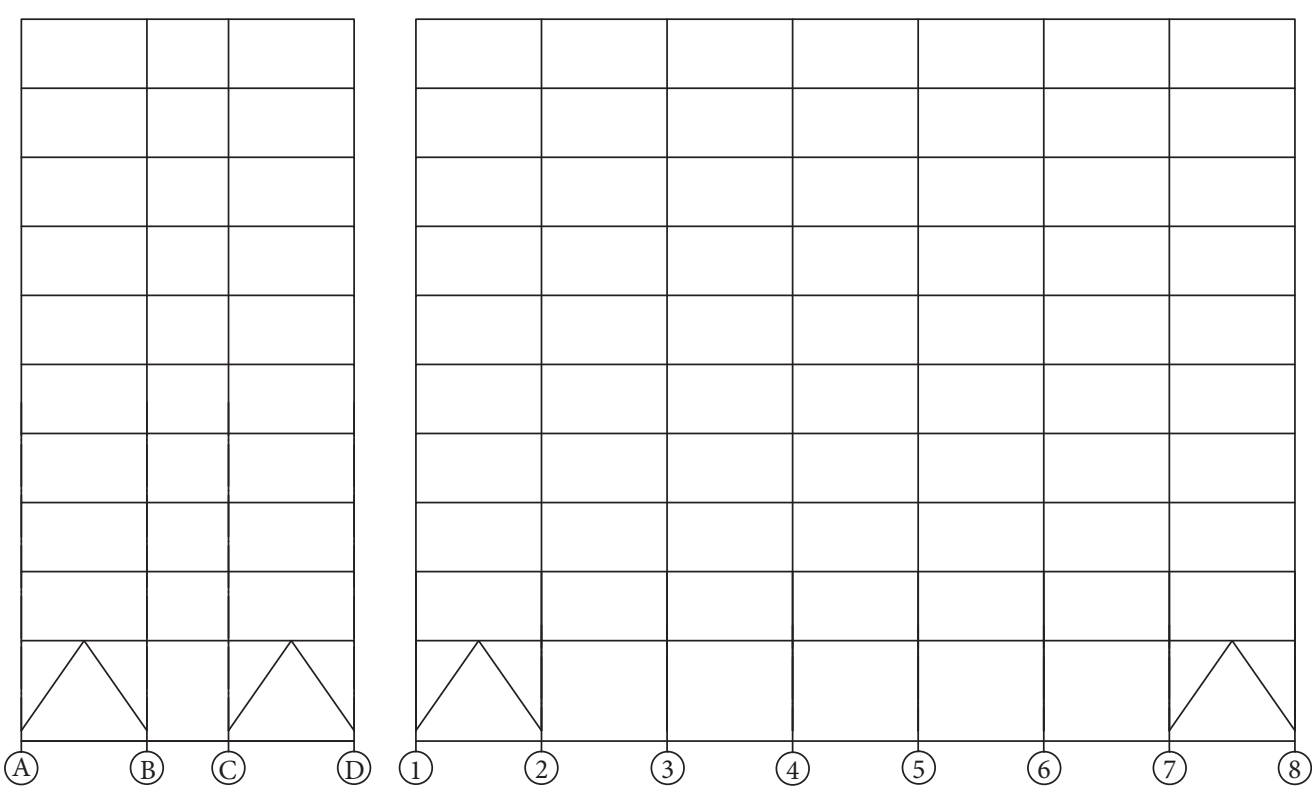

FIGURE 2: BRB layout added to the bottommost layer.

\section{Near-Fault Ground Motion Selection}

To study the seismic response of the soft-first-storey frame structure under near-fault ground motion, 4 near-fault pulse-free ground motions and 8 near-fault pulsed ground motions were selected from the strong-earthquake database of the US Pacific Earthquake Engineering Research Center (http://ngawest2.berkeley.edu). The ground motion information is shown in Table 2. The principle of primary selection for near-fault ground motion is as follows [20-22]: (1) the distance from the site to the surface projection point of the fault surface is less than $20 \mathrm{~km}$; (2) the V30 is 

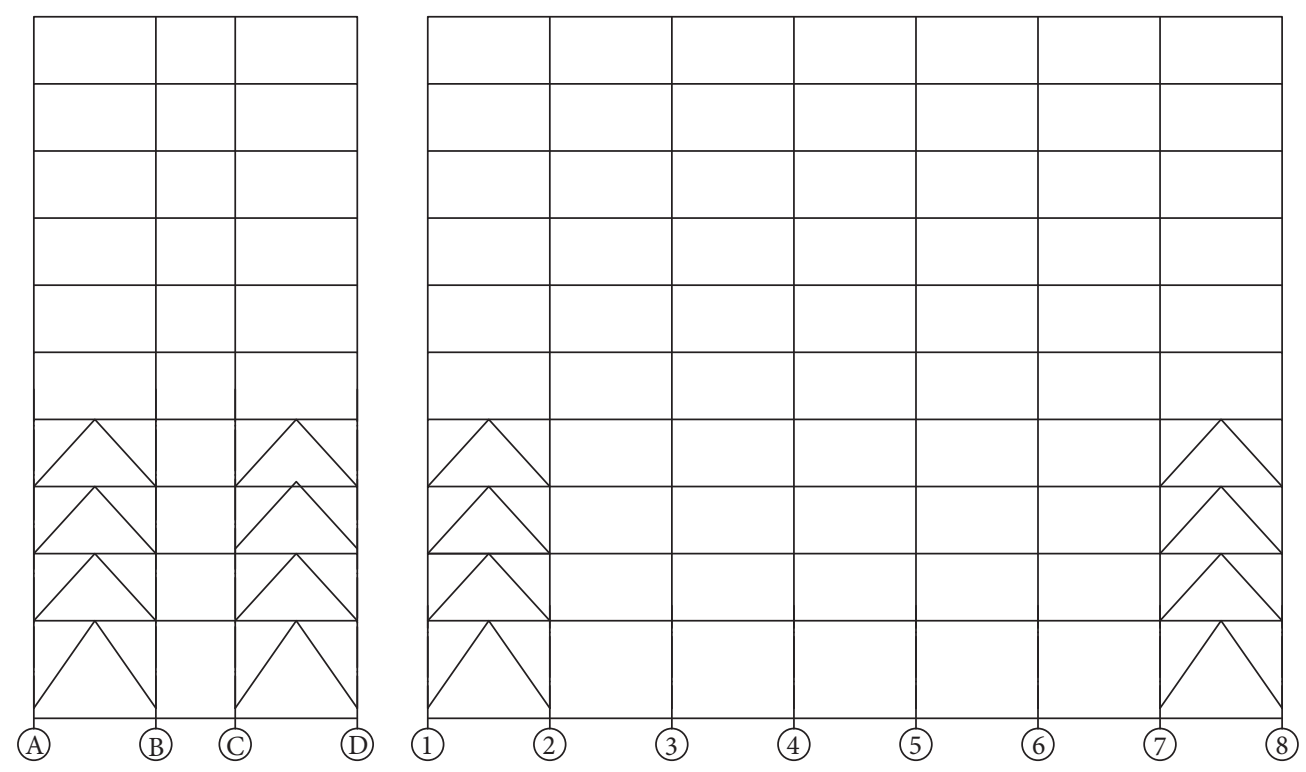

FIgURe 3: BRB layout added to the bottom four floors.

TABLE 2: Near-fault ground motion information.

\begin{tabular}{|c|c|c|c|c|c|c|c|}
\hline Type & RSN & Station & Magnitude & $R_{j b}(\mathrm{~km})$ & PGA (g) & $T_{s}(\mathrm{~s})$ & $T_{p}(s)$ \\
\hline \multirow{8}{*}{ Near-fault pulse ground motion } & 1510 & TCU075 & 7.62 & 0.89 & 0.33 & 0.36 & 4.998 \\
\hline & 983 & JGB022 & 6.69 & 5.43 & 0.57 & 0.36 & 3.535 \\
\hline & 147 & G02140 & 6.53 & 8.47 & 0.26 & 0.35 & 1.463 \\
\hline & 767 & G03090 & 6.93 & 12.23 & 0.37 & 0.23 & 2.639 \\
\hline & 802 & STG090 & 6.93 & 7.58 & 0.33 & 0.20 & 4.571 \\
\hline & 828 & PET000 & 7.01 & 8.18 & 0.59 & 0.67 & 2.996 \\
\hline & 3746 & CBF360 & 7.01 & 16.44 & 0.48 & 0.24 & 1.967 \\
\hline & 568 & GIC090 & 5.80 & 2.14 & 0.71 & 0.27 & 0.805 \\
\hline \multirow{4}{*}{ Near-fault no-pulse ground motion } & 779 & LGP090 & 6.93 & 3.88 & 0.31 & 0.40 & - \\
\hline & 989 & CHL070 & 6.69 & 9.87 & 0.22 & 0.42 & - \\
\hline & 587 & MAT083 & 6.60 & 16.09 & 0.28 & 0.38 & - \\
\hline & 1012 & LA0180 & 6.69 & 9.87 & 0.26 & 0.38 & - \\
\hline
\end{tabular}

controlled in the range of $260-510 \mathrm{~m} / \mathrm{s}$, corresponding to a Class II site in the code for seismic design of buildings [19]; and (3) to reflect the strong-earthquake characteristics of near-fault ground motion, the ground motion record has a moment magnitude greater than 5.5, and the ground peak acceleration of each ground motion should be greater than $0.15 \mathrm{~g}$. The velocity pulse characteristic is discriminated based on the identification method proposed by JW Baker. When the relationship pulse indicator $=1 /\left(1+e^{-23.3+14.6 P G V_{\text {ratio }}+20.5\left(E_{\text {ratio }}\right)}\right)$ is greater than 0.85 , the velocity of the original record is greater than $30 \mathrm{~cm} /$ $s$, and the record occurs in the early stage of the speed history, it is classified as a pulse-type ground motion.

After the primary ground motion was completed, the peak value of the selected ground motion acceleration was adjusted to $310 \mathrm{~cm} / \mathrm{s}^{2}$, which corresponds to a seven-degree rare earthquake. The acceleration response spectrum is shown in Figure 4. The seismic influence coefficients of the 4 near-fault pulse-free ground motions were $0.227,0.235$, and 0.25 , respectively, at the first three-order mode periodic control points, and the differences between these coefficients and the regulated seismic impact coefficients were 15\%, 13\%, and $11 \%$, respectively. On the other hand, the seismic influence coefficients of the 8 near-fault pulse-type ground motions were $0.266,0.271$, and 0.290 , respectively, at the first three-order mode periodic control points, and the differences between these coefficients and the regulated seismic impact coefficients were all within $2 \%$. Through this analysis, these ground motions can meet the requirements of the code for seismic design of buildings and can be used for time history analysis.

\section{Seismic Response Analysis}

5.1. Interlayer Displacement Angle Analysis. The interlayer displacement angle responses of the unsupported structure under near-fault pulse-type ground motion and near-fault pulse-free ground motion are shown in Figures 5(a) and 5 (b), respectively. As can be seen from the figure, under the action of near-field ground motion, the interlayer displacement demand values between layers in the 1st-5th layers were relatively large, with the interlayer displacement 


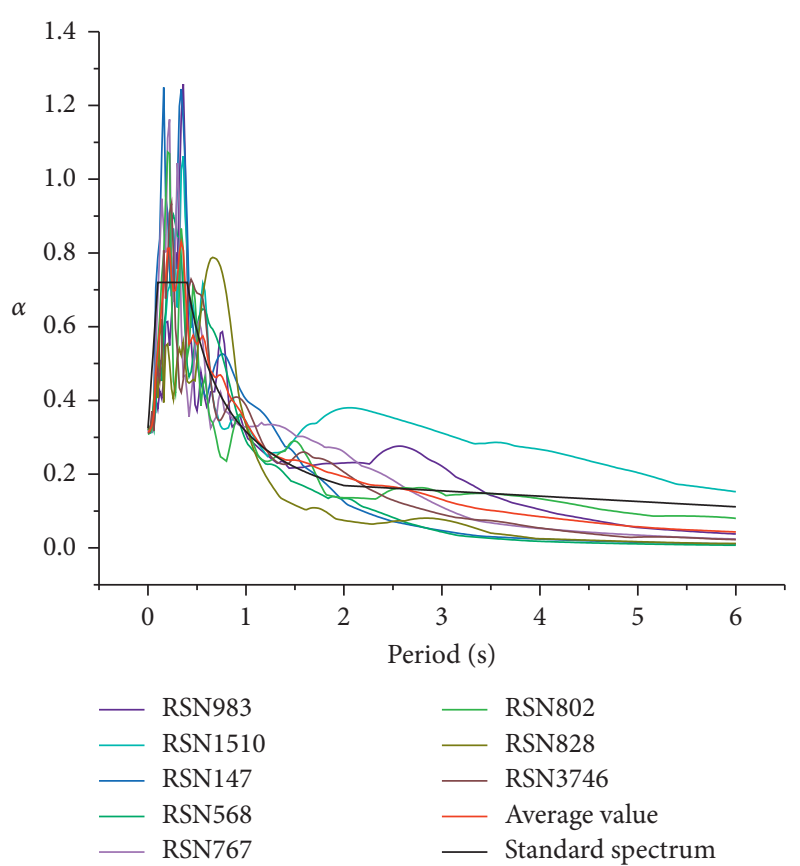

(a)

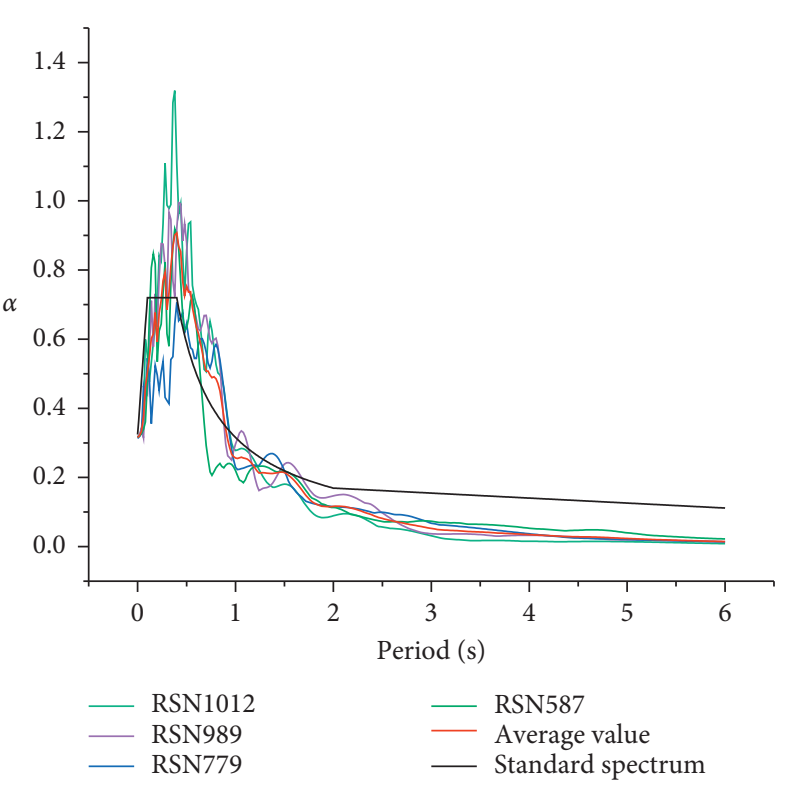

(b)

FIGURE 4: Comparison of acceleration response spectrum and normative spectrum. (a) Near-field pulse-type ground motion. (b) Near-field pulse-free ground motion.

demand at the bottom being the largest. Under the action of the near-fault pulsed ground motion measured at RSN1510, the underlying interlayer displacement angle of the unsupported structure exceeded the elastoplastic interlayer displacement angle limit indicated in the specification. Above the 6th layer, the interlayer displacement of the structure was small, the displacement angles between the layers were mostly within $1 / 550$, and the beams and columns were not damaged. The response to structural interlayer displacement is largest under pulsed ground motion near faults, followed by that under pulse-free ground motion near faults.

To more intuitively reflect the influence of two kinds of ground motion on the structural interlayer displacement response, the average values of the structural interlayer displacement angles were calculated and compared. The average interlayer displacement angles are shown in Figure 5(c). According to the figure, the displacement angle of the bottom layer under near-fault pulse-type ground motion is about twice that under near-fault pulse-free ground motion; this result fully demonstrates that near-fault pulse-type ground motion will cause more serious damage to the soft-first-storey frame structure.

The interlayer displacement angles of the bottom-support structure under near-fault pulse-type ground motion and near-fault pulse-free ground motion are shown in Figures 6(a) and $6(\mathrm{~b})$, respectively. Figure $6(\mathrm{c})$ is a comparison of the average interlayer displacement angles of the bottom-support structure and unsupported structure under the action of these two types of ground motion. In the chart, Model 1 represents the unsupported structure, Model 2 represents the bottomsupport structure, and Model 3 represents the bottom-four- layer-support structure. As can be seen from the figure, after support was added to the bottom layer, the interlayer displacement angles between the 2 layers at the bottom under the action of two types of ground motion were significantly reduced, the interlayer displacement angles between the 3rd and 6th layers were slightly increased, and the interlayer displacement angles between the 6th layer and the layers above it did not exceed the displacement angle between the elastic layers; the maximum displacement angle between the layers was measured at the 3 rd layer. Under near-fault pulse-type ground motion, the interlayer displacement angles between the 1 st layer and 2 nd layer were reduced by $73 \%$ and $26 \%$, respectively; under the action of no-pulse ground motion, the same angles were reduced by $57 \%$ and $27 \%$, respectively. The comparison results demonstrate that the BRB dampers can effectively reduce the interlayer displacement reaction at the bottom weak layer; the 3rd layer then became the weak layer because of the improvement of bottom-layer stiffness.

The interlayer displacement angles of the bottom-fourlayer-support structure under near-fault pulse-type ground motion and near-fault nonpulsating ground motion are shown in Figures 7(a) and 7(b), respectively. Figure 7(c) is a comparison of the average interlayer displacement angles of the bottom-four-layer-support structure and unsupported structure under two types of ground motion. As can be seen from the figure, after support was added to the first four layers, the interlayer displacement angles between the 3 layers at the bottom were significantly reduced and were not very different from each other, the interlayer displacement angles between the 4th and 6th layers were slightly increased, and the interlayer displacement angles between the 7th layer and the layers above it were in a safe range. Under near-fault 


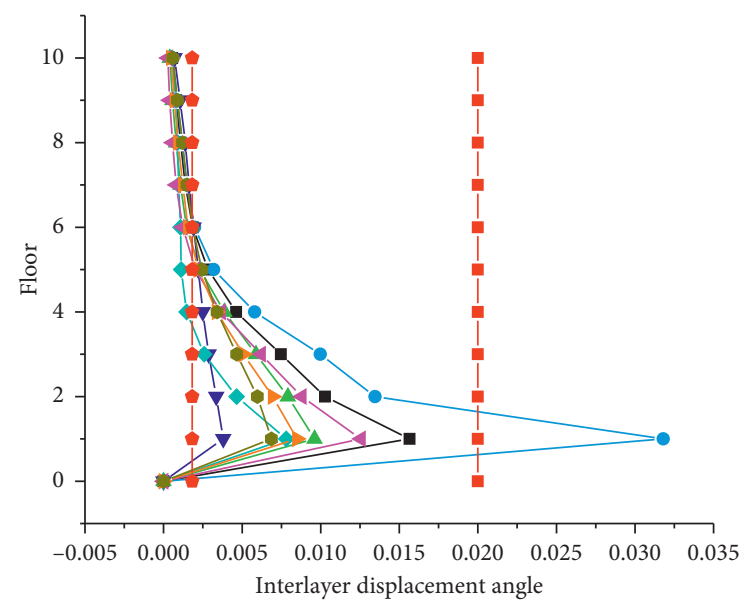

(a)

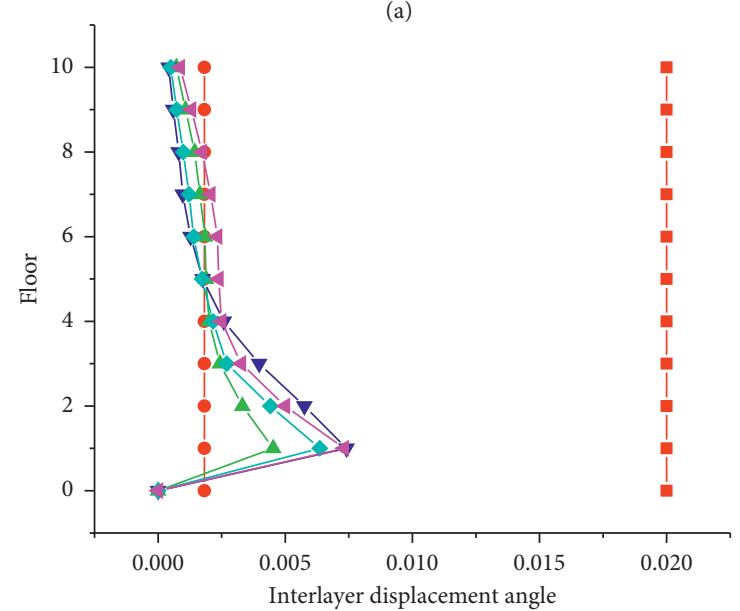

(b)

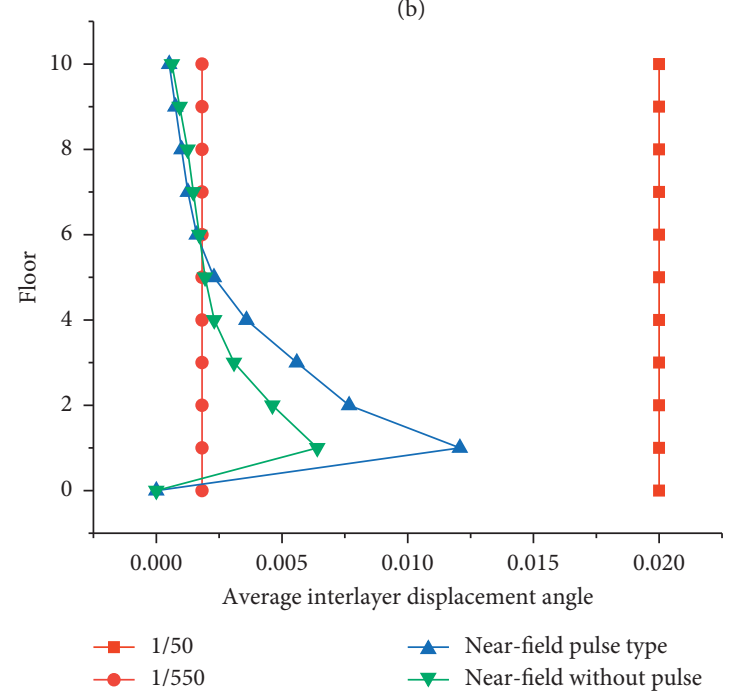

(c)

FIGURE 5: Interlayer displacement angles of unsupported structure. (a) Near-field pulsed ground motion. (b) Near-field pulse-free ground motion. (c) Average interlayer displacement angles.

pulse-type ground motion, the interlayer displacement angles of the 1 st to 3 rd layers were reduced by $68 \%, 43 \%$, and $24 \%$, respectively; under the pulse-free ground motion near the fault, the interlayer displacement angles of the 1st to 3rd

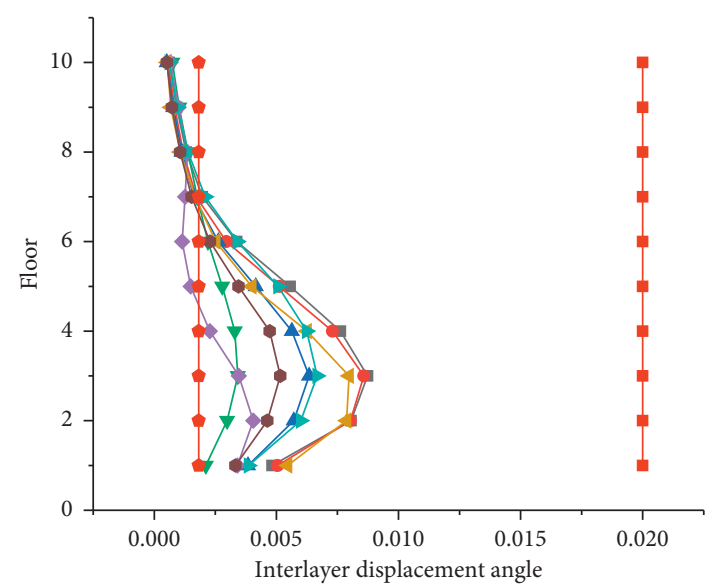

(a)

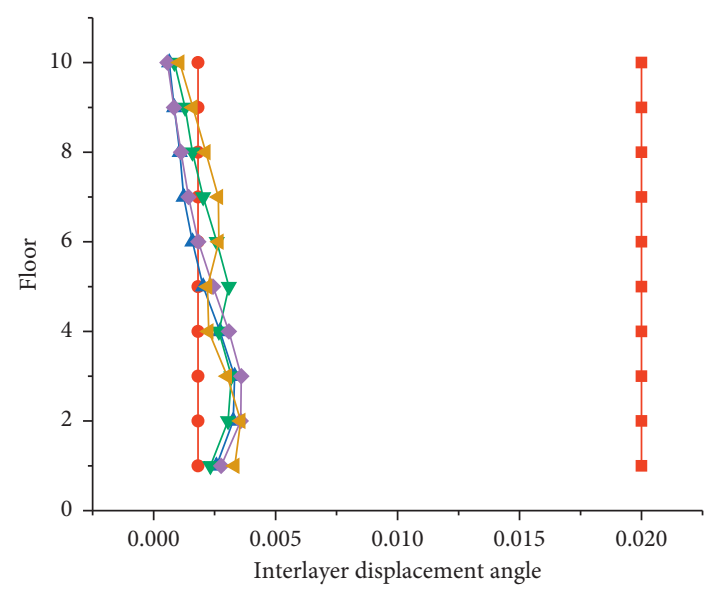

(b)

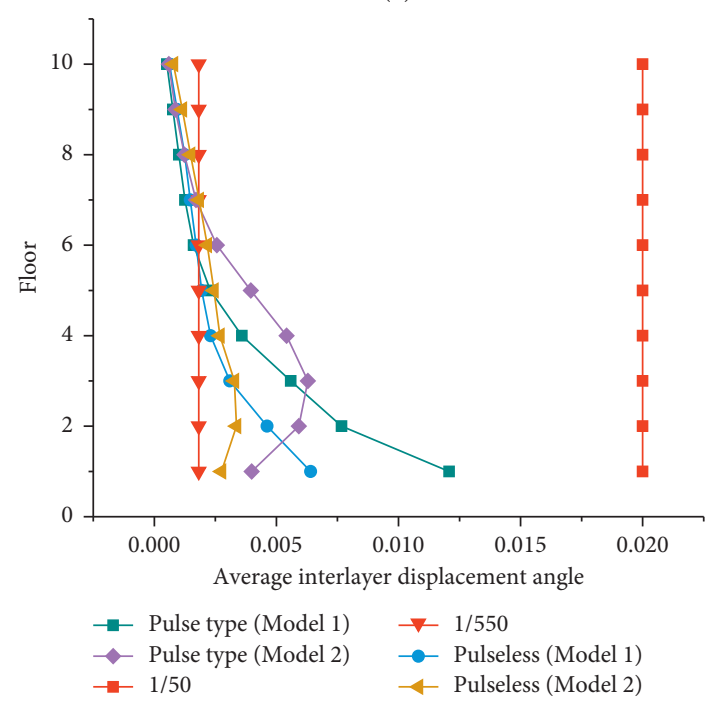

(c)

FIGURE 6: Interlayer displacement angles of bottom-layer-plus-support structure. (a) Near-field pulsed ground motion. (b) Near-field pulse-free ground motion. (c) Average interlayer displacement angles.

layers were reduced by 55\%, 34\%, and 3\%, respectively. This result fully demonstrates that the seismic performance of the structure was significantly improved after support was added to the 1st to 4th layers; the underlying weak layer was eliminated, but the upper floor did not turn into a weak layer. 


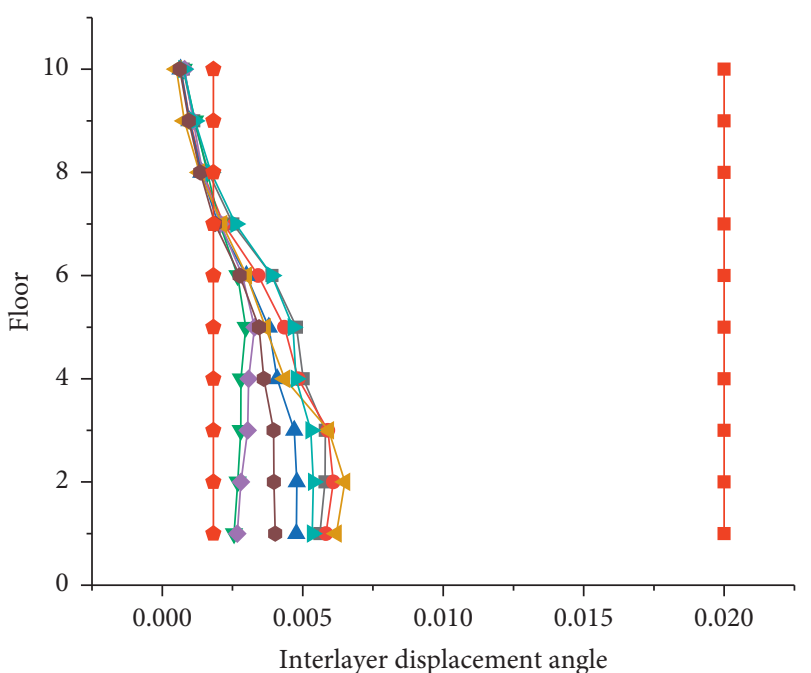

(a)

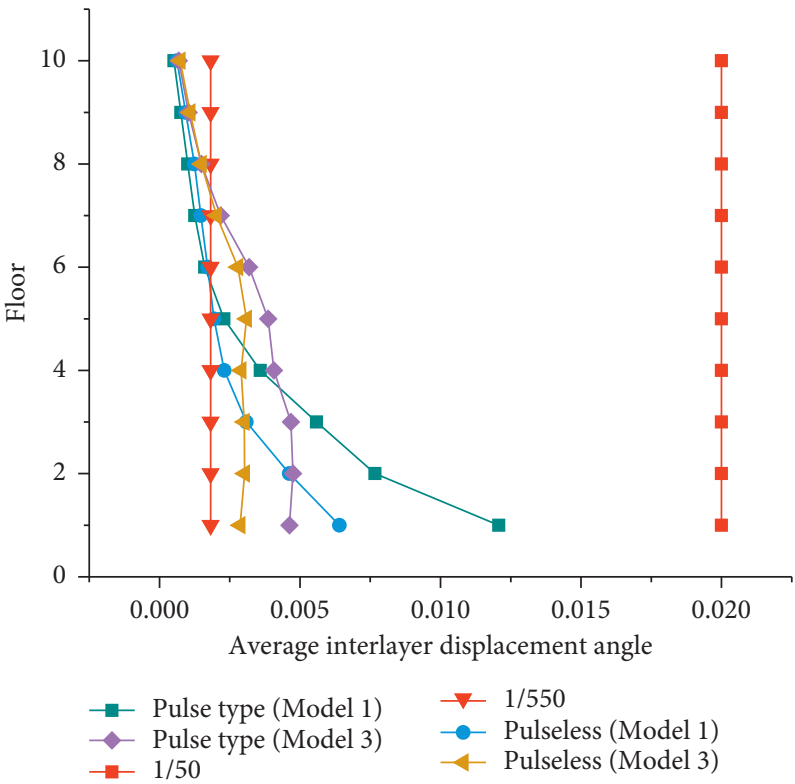

(c)

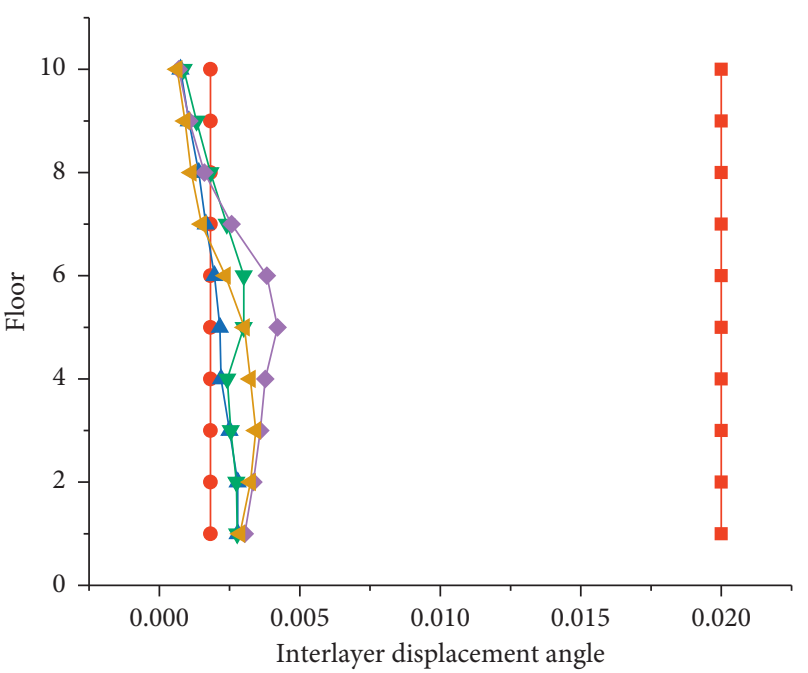

(b)

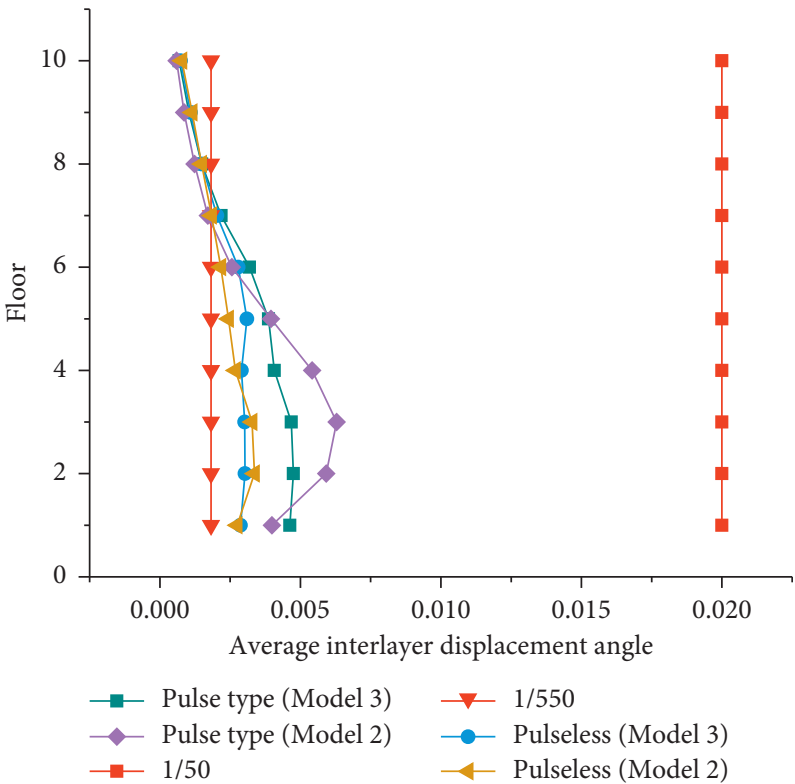

(d)

FIGURE 7: Interlayer displacement angles of the bottom-four-layers-plus-support structure. (a) Near-field pulsed ground motion. (b) Nearfield pulse-free ground motion. (c) Average interlayer displacement angles, comparison with unsupported structure. (d) Average interlayer displacement angles, comparison with bottom-support structure.

Figure $7(\mathrm{~d})$ is a comparison of the average interlayer displacement angles between the bottom-four-layer-support structure and bottom-support structure under two kinds of ground motion. Relative to the structure supported only at the bottom, when the bottom four layers were supported, the distribution of the interlayer displacement angles was more uniform, there was no obvious weak part in the structure, except for the slight increase in the interlayer displacement angles between the bottom layers, the interlayer displacement angles between the 2nd and 5th layers were obviously reduced, and those between the 6th and 10th layers were obviously unchanged. Relative to the bottom-support structure, under the action of near-fault pulse-type ground motion, the interlayer displacement angles of the 2nd to 5th layers of the bottom-fourlayer-support structure were reduced by $22 \%, 29 \%, 31 \%$, and
$12 \%$, respectively. This result demonstrates that the shock absorption effect of adding support to the bottom four layers is better than that of adding support only to the bottommost layer.

5.2. Maximum Acceleration and Displacement Response Analysis of the Bottommost Layer. The unsupported structure, bottom-support structure, and bottom-four-layersupport structure were compared with respect to the results for the maximum acceleration values and maximum displacement values of the bottommost layer under the action of the two kinds of ground motion, as shown in Table 3. In the table, Model 1 represents the unsupported structure, Model 2 represents the bottom-support structure, and Model 3 represents the bottom-four-layer-support structure. 
TABLE 3: Comparison of the maximum acceleration and displacement results of the bottommost layer.

\begin{tabular}{|c|c|c|c|c|c|c|c|}
\hline \multirow[t]{2}{*}{ Ground motion type } & & \multicolumn{3}{|c|}{$\begin{array}{l}\text { Maximum acceleration of the } \\
\text { bottom layer }\left(\mathrm{m} / \mathrm{s}^{2}\right)\end{array}$} & \multicolumn{3}{|c|}{$\begin{array}{l}\text { Maximum displacement of the } \\
\text { bottom layer }(\mathrm{mm})\end{array}$} \\
\hline & & Model 1 & Model 2 & Model 3 & Model 1 & Model 2 & Model 3 \\
\hline \multirow{10}{*}{ Near-fault pulsed ground motion } & 802 & 2.67 & 2.47 & 2.51 & 33.6 & 14.6 & 11.5 \\
\hline & 983 & 2.11 & 1.84 & 2.00 & 41.3 & 16.5 & 20.5 \\
\hline & 147 & 3.39 & 3.03 & 3.22 & 53.9 & 23.5 & 26.6 \\
\hline & 3746 & 1.75 & 1.48 & 1.48 & 36.5 & 16.6 & 22.9 \\
\hline & 767 & 2.84 & 3.09 & 3.29 & 67.3 & 20.8 & 24.1 \\
\hline & 1510 & 2.14 & 2.00 & 2.26 & 136 & 21.7 & 25.0 \\
\hline & 568 & 2.33 & 1.85 & 2.21 & 29.5 & 14.3 & 17.2 \\
\hline & 828 & 2.01 & 1.83 & 1.82 & 16.4 & 9.07 & 10.9 \\
\hline & Average value & 2.41 & 2.19 & 2.34 & 51.8 & 17.1 & 19.8 \\
\hline & Reduction rate & - & $9 \%$ & $3 \%$ & - & $67 \%$ & $62 \%$ \\
\hline \multirow{6}{*}{ Near-fault no-pulse ground motion } & 779 & 1.83 & 1.73 & 1.77 & 31.8 & 10.0 & 11.9 \\
\hline & 989 & 2.43 & 2.06 & 2.08 & 27.3 & 11.9 & 13.1 \\
\hline & 587 & 2.25 & 1.99 & 2.21 & 19.5 & 11.1 & 12.0 \\
\hline & 1012 & 2.84 & 2.26 & 2.39 & 31.4 & 14.3 & 12.3 \\
\hline & Average value & 2.33 & 2.01 & 2.11 & 27.5 & 11.8 & 12.3 \\
\hline & Reduction rate & - & $14 \%$ & $10 \%$ & - & $57 \%$ & $55 \%$ \\
\hline
\end{tabular}
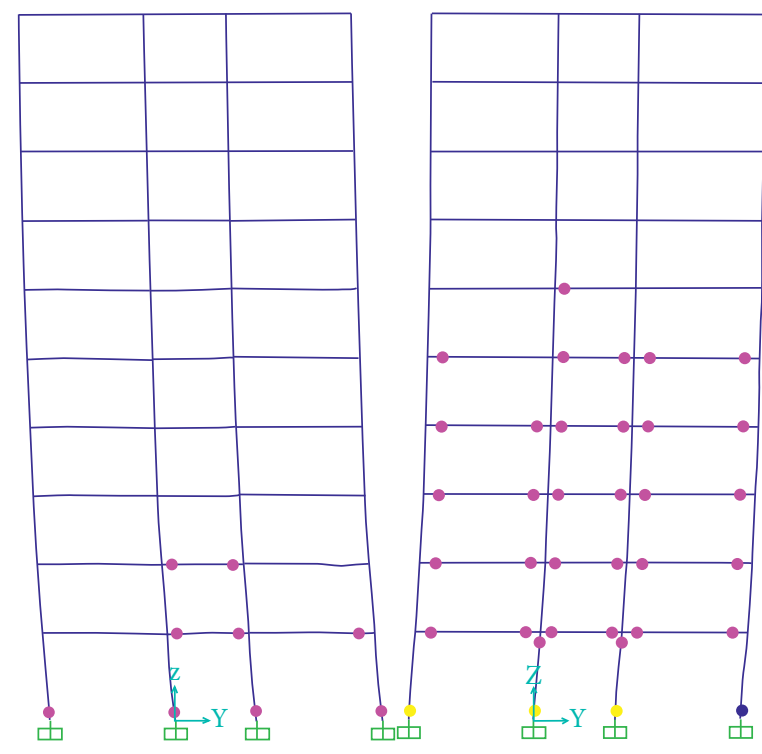

(a)

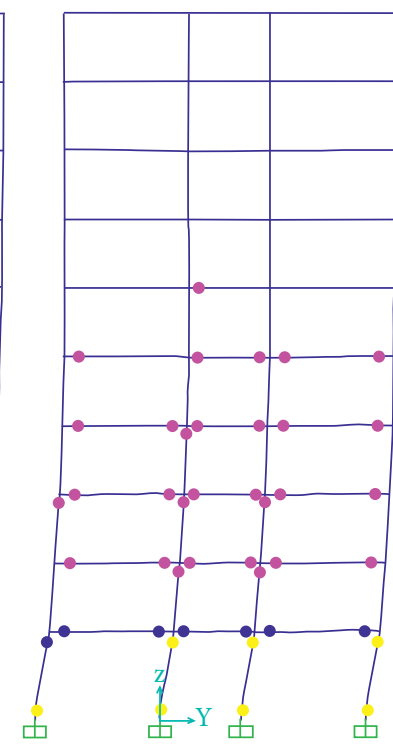

E

D

C

$\mathrm{CP}$

LS

IO

B

Figure 8: Continued. 

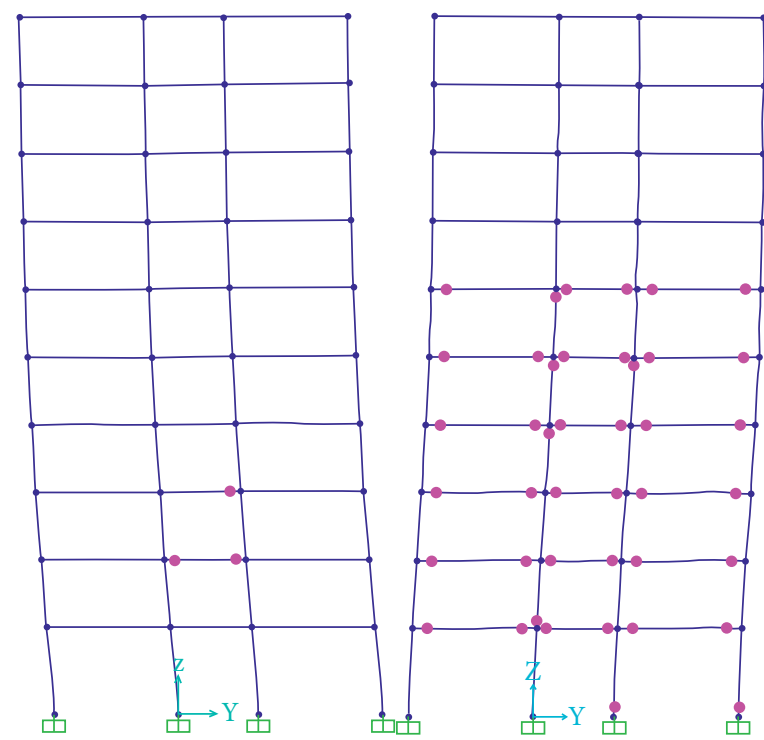

(b)
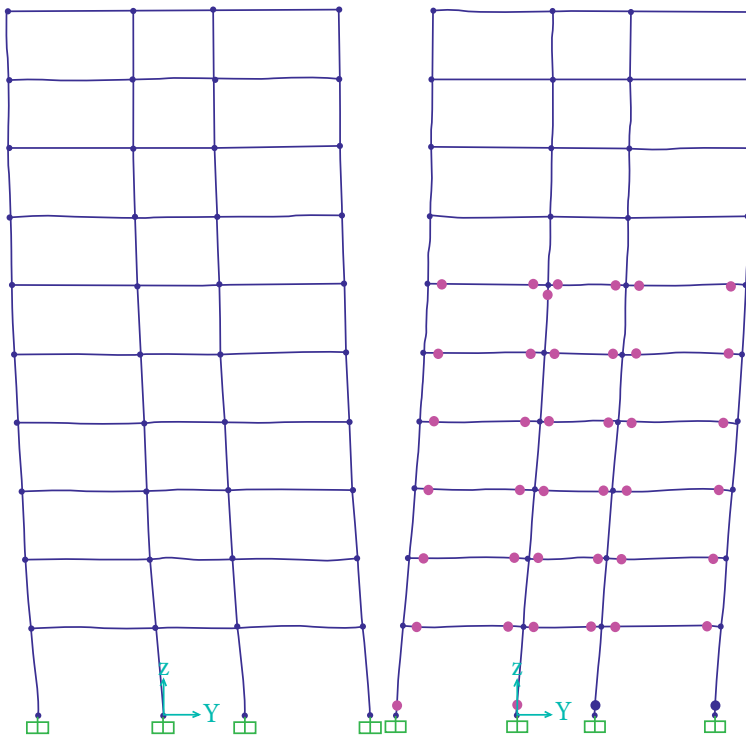

(c)

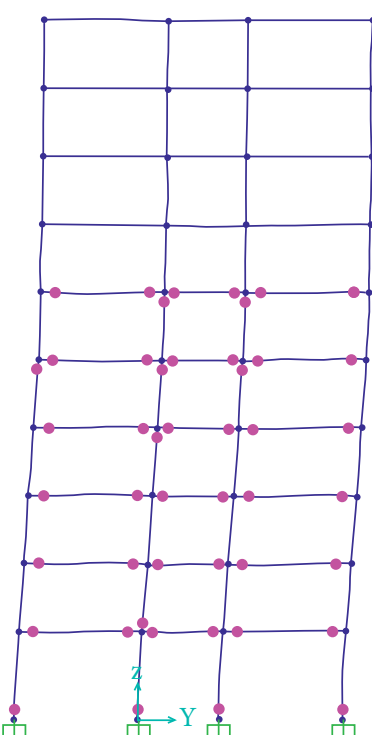

E

$\mathrm{D}$

C

$\mathrm{CP}$

LS

IO

B

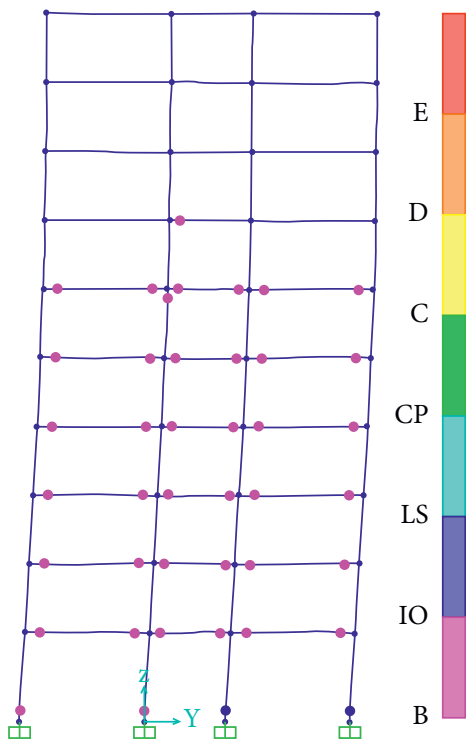

Figure 8: Development and distribution of plastic hinges. (a) Model 1. (b) Model 2. (c) Model 3.

In Table 3, the maximum displacement values of the bottomsupport structure and bottom-four-layer-support structure, under the action of the two kinds of ground motion, are noticeably significantly reduced compared with those of the unsupported structure, with average reduction rates able to reach more than $55 \%$. Under the action of near-fault pulsetype ground motion, the mean reduction rates of the maximum acceleration values of the bottom-support structure and bottom-four-layer-support structure are 9\% and 3\%, respectively, compared with those of the unsupported structure, and the mean reduction rates were $14 \%$ and $10 \%$, respectively, under near-fault nonpulsating ground motion. These results demonstrate that when BRB dampers were added to the soft-first-storey frame structure, the amplification effect of the structure on seismic excitation was reduced, and the weakening characteristics of the bottommost layer were significantly improved. The seismic performance under near-fault ground motion was also greatly improved.

5.3. Analysis of Damage on Plastic Hinges of Beams and Columns. The damages on beams and columns under nearfault pulsed ground motion at RSN767 were illustrated using the development of plastic hinges in the three models. Figure 8 shows the development of plastic hinges in a transverse frame at the beginning, middle, and end of ground motion loading.

A comparison of the three models was performed. For the unsupported structure, plastic hinges were found to be present all over the bottom of a layer of columns in the initial 


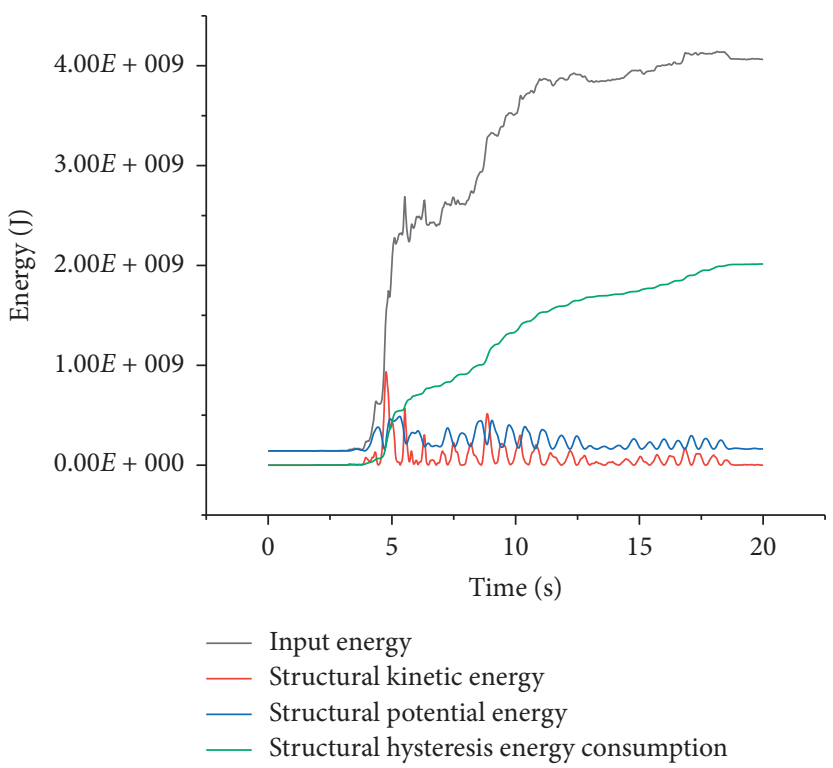

(a)

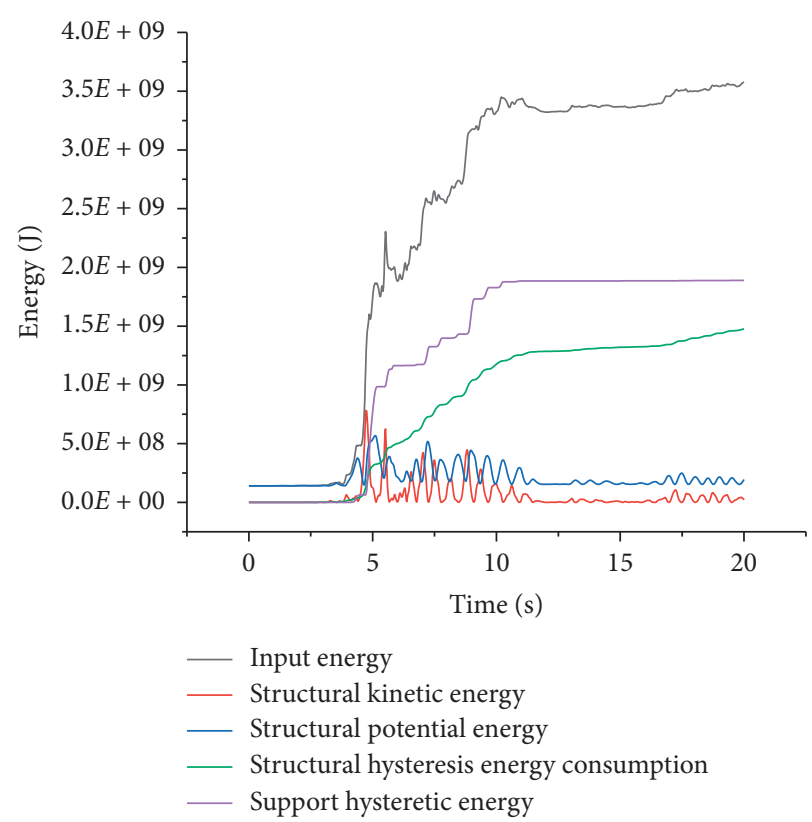

(b)

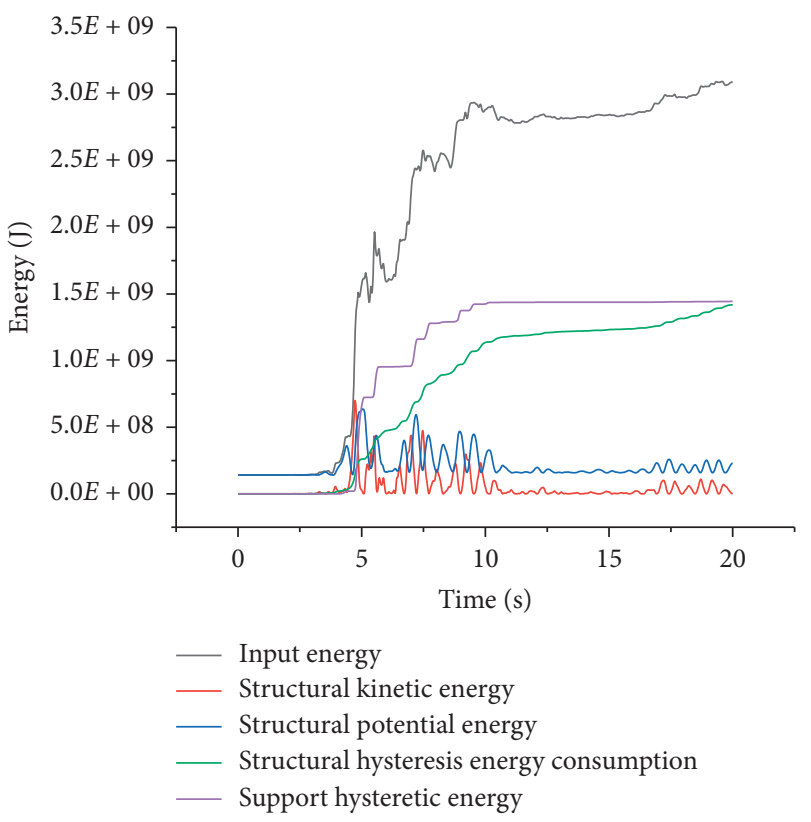

(c)

FIGURE 9: Schematic diagram of energy distribution of structure under RSN767 ground motion. (a) Model 1. (b) Model 2. (c) Model 3.

stage of ground motion loading. However, for the bottomsupport structure and bottom-four-layer-support structure, there were no plastic hinges at the bottoms of the columns. In addition, for the bottom-four-layer-support structure, plastic hinges were also not present in the beams, and the development of beam-column plastic hinges was well suppressed.

For the unsupported structure, most of the plastic hinges at the bottom of the first-floor column reached their ultimate bearing capacity state in the middle stage of ground motion loading. However, after the BRB dampers were added to the soft-first-storey frame structure, the plastic hinges at the bottom of the first-floor column were in the stage of just yielding and immediate use, and a large safety reserve was present. In the unsupported structure, at the end of ground motion loading, plastic hinges appeared simultaneously at the bottoms and tops of the columns in the first layer, most of which reached the state of ultimate bearing capacity, exhibiting an interlaminar failure mechanism. Plastic hinges were also present in the middle columns of the 2 nd to 4 th layers. However, with the addition of BRB dampers, the failure degree of plastic hinges at the bottom of the layer of columns was not further developed, and plastic hinges were not present in the columns above the first floor. This result demonstrates that 
the inclusion of BRB dampers in the soft-first-storey frame structure can effectively inhibit the development of plastic hinges in beams and columns and reduce damage on the main structure.

5.4. Energy Distribution. With the action of near-fault ground motion at RSN767 taken as an example, the energy distributions of the bottom-support structure and bottomfour-layer-support structure were illustrated. The energy distribution diagrams are shown in Figure 9. The hysteretic energy consumption of the unsupported structure accounts for about $50 \%$ of the total energy of the seismic input structure. On the other hand, the hysteretic energies of the bottom-support structure and bottom-four-layer-support structure account for $39 \%$ and $43 \%$, respectively, of the total energies of their seismic input structures, and the hysteretic energy consumptions of the main structures were reduced. The support hysteresis energies of the bottom-support structure and bottom-four-layer-support structure account for about $54 \%$ and $53 \%$, respectively, of the total energies of their seismic input structures. The energy dissipation effect of BRB dampers was obvious, demonstrating the ability of being better able to protect the main structure.

\section{Conclusion}

Based on the analysis performed in this research, the conclusions of this study are as follows:

(1) Under the action of near-fault pulse-type ground motion, the seismic response of the soft-first-storey frame structure is obviously larger than that under nonpulsed ground motion, and the plastic hinge damages on the beams and columns are more serious and develop more rapidly. The displacement angle of the bottommost layer under near-fault pulse-type ground motion is about twice that under nonpulsed ground motion.

(2) After buckling-restrained brace (BRB) dampers were added to the soft-first-storey frame structure, the displacement angle, maximum acceleration, and maximum displacement of the bottommost layer under the action of the two types of ground motion are significantly reduced, effectively reducing the seismic response of the structure, greatly improving the seismic performance, and reducing the damage of the main structure in case of an earthquake.

(3) Compared with the structure in which the BRB dampers are arranged only in the bottommost layer, the bottom-four-layer-support structure is more advantageous in terms of seismic performance. The BRB dampers have an obvious energy consumption effect, can better protect the main structure, and have good practicability.

\section{Data Availability}

The data used to support the findings of this study are included within the article. Analytical data mainly includes the interlayer displacement angle, the maximum acceleration and displacement, the development of plastic hinges, and the energy distribution.

\section{Conflicts of Interest}

The authors declare that they have no conflicts of interest.

\section{Acknowledgments}

The authors are grateful to the Key Laboratory of Building Structural Retrofitting and Underground Space Engineering (Shandong Jianzhu University) and Ministry of Education for accommodating the use of the equipment and facilities. This work was supported by the Natural Science Foundation of Shandong Province (Grants nos. ZR2015EQ017 and ZR2018MEE044).

\section{References}

[1] X. L. Du, J. F. Jia, and Q. Han, "A state-of-the-art review of near-fault earthquake ground motion characteristics and effects on engineering structures," Journal of Building Structures, vol. 36, no. 1, pp. 1-12, 2015.

[2] Q. F. Liu, Y. F. Yuan, X. Ji et al., "Basic characteristics of nearfault ground motion," Earthquake Engineering and Engineering Dynamics, vol. 26, no. 1, pp. 1-10, 2006.

[3] Z. C. Li, X. L. Chen, J. Wu et al., "Engineering seismic parameters characteristic analysis of Hualian earthquake (Ms6.5) in Taiwan region," Building Structure, vol. 48, no. S2, pp. 308-313, 2018.

[4] P. Pan, L. P. Ye, X. Z. Lu et al., "Analysis of the damage mechanism of a typical RC frame in Wenchuan earthquake," China Civil Engineering Journal, vol. 42, no. 5, pp. 13-20, 2018.

[5] M. Yoshimura, "Nonlinear analysis of a reinforced concrete building with a soft first story collapsed by the 1995 Hyogoken-Nanbu earthquake," Cement and Concrete Composites, vol. 19, no. 3, pp. 213-221, 1997.

[6] F. Watanabe, "Behavior of reinforced concrete buildings during the Hyougoken-Nanbu earthquake," Cement and Concrete Composites, vol. 19, no. 3, pp. 203-211, 1997.

[7] W. L. Cao, J. M. Liu, and D. Z. Wang, "Study on rational setting of bottom support for special-shaped column frame structure," Earthquake Engineering and Engineering Dynamics, vol. 17, no. 1, pp. 77-82, 1997.

[8] J. Esfandiari and P. Loghmani, "Effect of perlite powder and silica fume on the compressive strength and microstructural characterization of self-compacting concrete with lime-cement binder," Measurement, vol. 147, Article ID 106846, 2019.

[9] A. R. Rahai and M. M. Alinia, "Performance evaluation and strengthening of concrete structures with composite bracing members," Construction and Building Materials, vol. 10, no. 22, pp. 2100-2110, 1997.

[10] Q. Z. Ge and H. Ma, "Seismic research on soft-first story structure with fiber concrete damper," Earthquake Resistant Engineering and Retrofitting, vol. 34, no. 5, pp. 20-26, 2012.

[11] O. Lavan and R. Levy, "Optimal design of supplemental viscous dampers for irregular shear-frames in the presence of yielding," Earthquake Engineering \& Structural Dynamics, vol. 34, no. 8, pp. 889-907, 2008.

[12] Z. B. Li, H. Ma, W. B. Yan, and X. Zhou, "Seismic behavior of frame with RC dampers and lock-up braces," Building Structure, vol. 38, no. 11, pp. 65-67, 2008. 
[13] J. Esfandiari and E. Soleimani, "Laboratory investigation on the buckling restrained braces with an optimal percentage of microstructure, polypropylene and hybrid fibers under cyclic loads," Composite Structures, vol. 203, pp. 585-598, 2018.

[14] Y. Wu, M. G. He, Y. Zhou et al., "Analysis of aseismic performances of SRC transfer structure with supplemental energy dissipation haunch brace," Earthquake Resistant Engineering and Retrofitting, vol. 32, no. 2, pp. 68-74, 2010.

[15] W. D. Lu, Z. J. Lan, and W. Q. Liu, "Design method of damped bracings to control the structure with weak story," Earthquake Resistant Engineering and Retrofitting, vol. 33, no. 2, pp. 5762, 2011.

[16] P. Pan, H. Y. Cao, Y. J. Qi et al., "Retrofit of soft first story structure using seismic isolation technology," Earthquake Resistant Engineering and Retrofitting, vol. 31, no. 6, pp. 6973, 2009.

[17] Y. L. Mo and Y. F. Chang, "Application of base isolation concept to soft first story buildings," Computers \& Structures, vol. 55, no. 5, pp. 883-896, 1995.

[18] A. Qi, Y. X. Wu, and X. Y. Yan, "Performance analysis of isolation on the top of columns for first-floor weak framestructure," Journal of Nanchang University (Engineering Science), vol. 33, no. 4, pp. 365-369, 2011.

[19] The Ministry of Construction of the Peoples Republic of China GB50011-2010: Code for Seismic Design of Buildings, China Architecture and Building Press, Beijing, China, 2016.

[20] M. Han, Y. L. Duan, H. Sun et al., "Influence of characteristics parameters of near-fault ground motions on the seismic responses of base-isolated structures," China Civil Engineering Journal, vol. 46, no. 6, pp. 8-13, 2013.

[21] H. S. Lu and F. X. Zhao, "Amplification coefficient of ground motion response spectrum applicable to Chinese site classification," Acta Seismologica Sinica, vol. 29, no. 1, pp. 67-76, 2007.

[22] J. W. Baker, "Quantitative classification of near-fault ground motions using wavelet analysis," Bulletin of the Seismological Society of America, vol. 97, no. 5, pp. 1486-1501, 2007. 